\title{
SERGIO LEONE Y ENNIO MORRICONE: DESDE LOS PRIMEROS WESTERN HASTA ÉRASE UNA VEZ EN AMÉRICA
}

\author{
Ferrán Riesgo \\ Universidad de Alicante
}

We must grant the artist his subject, his idea, his donnée: our criticism is applied only to what he makes of it.

Henry James

\section{INTRODUCCIÓN}

El primer encuentro entre Sergio Leone y Ennio Morricone tiene lugar en un internado de Roma, durante la niñez de ambos. Aunque fueron amigos entonces, sus caminos se separaron, y se reencontrarían sólo muchos años después, en 1964, cuando Leone, tras su Coloso de Rodas, se interesa por la música de su antiguo amigo para su primer western. Mientras tanto, Morricone, el niño que a los nueve años había transcrito de oído la obertura de Der Freischtz, de Weber, había estudiado ya trompeta y composición (una combinación explosiva, a juicio de sus profesores) en el Conservatorio de Roma, y tenía amplia experiencia como arreglista de música pop y compositor para cine y teatro, labores en las que había oficiado más de artesano que de artista.

Ésta es una de las dos preguntas principales que el espectador puede hacerse al pensar en una labor como la de Leone y Morricone. Suele ocurrir con los compositores de cine que sus ingentes catálogos de obras (a día de hoy Morricone es responsable de más de cuatrocientas bandas sonoras) acentúe todavía más esta dicotomía: las condiciones habituales de trabajo de estos músicos, la supeditación al montaje y la creación de música al servicio del film parecen degradar al músico desde la categoría de artista a la de artesano, más o menos capaz, pero esencialmente un trabajador a sueldo. Radigales cuenta que Xavier Montsalvatge "destruyó todo lo que había escrito para el cine, consciente de que era un trabajo muy colateral en su carrera [...], medio de subsistencia económica en un momento determinado de su vida" (2008:25); una actitud, por cierto, que adoptaría Morricone respecto a sus años de 
arreglista de música ligera. Adorno/Eisler, más asertivos, aseveran que "ningún compositor serio se pasa al cine por razones que no sean las puramente materiales" (1981:75).

Gilles Deleuze, en La imagen-tiempo, plantea la otra cuestión central, el Ilamado "problema" de la música en el cine: "cuando el cine se hace sonoro y parlante, la música queda en cierto modo emancipada y puede cobrar vuelo, pero, ¿en qué consiste ese vuelo, esa emancipación?" (1996:315). ¿Es la música de cine una expresión plena, o un mero añadido en la postproducción? ¿Es concebible un punto intermedio, y es tal vez en éste donde podemos situar la labor de los italianos? ¿Cuál sería, en un nivel ideal, la función de la música en el cine?

"El ojo", explican Adorno/Eisler, "ha sido siempre un órgano de esfuerzo, trabajo, concentración; percibe una cosa determinada de una forma unívoca. Comparándola con él, el oído carece de concentración y resulta más bien pasivo" (39). "El oído", por el contrario, "se aferra a la esencia arcaica de la música, mientras que ésta está enzarzada en el proceso de racionalización" (Ibíd.). La incidencia de la música en el inconsciente del espectador, dado su alto índice de abstracción y su usual no-referencialidad, clarifica aún más la división de las funciones expresivas paralelas de la música y la imagen".

Para Tarkovski, "la música no sólo refuerza e ilustra un contenido vertido en imágenes paralelas a la música, sino que abre la posibilidad de una impresión nueva, cualitativamente distinta, del mismo material [...]. No se modifica el sentido del objeto, pero se le da una vivacidad suplementaria" (86). Sin embargo, el logro de semejantes niveles de sincronía entre lo que "dicen" la música y la imagen se ha dado pocas veces en la historia del cine, y cada vez menos según se acentuaba su carácter de objeto de comercio. En ese sentido, Adorno y Eisler entendían el uso inteligente de la música como el resultado de "un verdadero trabajo de equipo. Solamente se puede obtener una forma de cine inteligentemente organizada si el compositor coopera plenamente desde el principio de la fase de planificación, si formula sus propias ideas y se defiende contra toda pretensión extravagante o banal en vez de limitar sus funciones a las de la pura ejecución"(1948:173).

Esto viene a ser un resumen ante literam del modo de trabajar de Leone y Morricone. De hecho, el director explicó que, en cuanto pudo permitírselo, comenzó a encargar la música a Morricone antes de empezar a filmar: "hago componer la música antes de rodar la película, la utilizo durante el rodaje y el montaje. Es un material esencial de mi cine. Nunca dejo que Morricone lea el guión para que componga. Le cuento yo la historia" (Apud. Aguilar,147-148). Parece claro que con semejante método de trabajo la música queda imbricada como parte constituyente del film y no como una capa posterior, una etapa de la post-producción. Así, a juicio de Michel Chion, "la música no se somete a funciones, asignables y finitas, igual que no lo hacen el montaje o la interpretación de los actores [...]. Resulta un tanto abusivo hablar de música como "acompañamiento del filme», porque forma parte de él" (1997:192-193).

Estamos ante un enfoque (el de intelectuales como Adorno o el propio Tarkovski) marcadamente elitista de la cuestión de la música para cine. Películas como las de Leone, por su accesibilidad, vertiente lúdica y aparente ligereza (las tres primeras al menos) probablemente escapen de los estándares de dichos críticos. Todos ellos consideran, junto con Chion ${ }^{2}$, que la música en el cine incurre muchas veces en la sobrecarga y la gratuidad, y por buscar lo espec-

1 Para una lectura detallada sobre el tema, véase. Leonard B. Meyer (2.005), La emoción y el significado en la música, Madrid, Alianza.

2 Para una idea detallada de la cuestión, véase. Adorno/Eisler, 1981: 51-60, 75,y 171 y ss.; Tarkosvki, 2007:185 y ss.

Quaderns, 8 (2013), pp. 19-30 
tacular o remitirse a los moldes establecidos, pierde efectividad y altura artística. Podemos, no obstante, acercarnos a la obra conjunta de Leone y Morricone. Lo debemos hacer partiendo de sus propias premisas, y no de las nuestras: para Henry James, todo artista o creador tiene derecho a su propio proyecto, y lo que debe ser criticado es su modo de llevarlo a cabo.

\section{UNA POÉTICA PROPIA: LA TRILOGÍA DEL DÓLAR}

Podemos considerar la obra de Morricone, en primer lugar, desde el punto de vista de lo puramente sonoro. En general es donde ha hecho más hincapié la crítica: en las capas superficiales de su música para el western de Leone, lo más llamativo es su renovación de la plantilla instrumental. En 1964, la música de cine suele consistir o bien en composiciones para orquesta de corte sinfónico, con preponderancia de la cuerda y tratado armónico moderno (que no vanguardista, salvo raras excepciones), o bien en canciones contemporáneas que se insertan en la banda sonora.

La música compuesta para la trilogía, empezando por Por un puñado de dólares (Per un pugno di dollari) más que transgredirlas, sencillamente ignora estas convenciones. El tema principal, con la melodía silbada y la introducción de sonidos extra-musicales (una máquina de escribir, un restallido como de fusta...), es una evolución de materiales que el compositor ya había producido para los arreglos de canciones pop en los que trabajaba en la época: Leone conocía estos trabajos, llamaron su atención, y juntos reelaboraron el tema de los créditos iniciales. Aun así es posible que lo más rompedor de esta partitura sea la incorporación de una guitarra eléctrica en limpio: desde los primeros diseños de Fender, Rickenbaker o Les Paul en los años treinta, la guitarra eléctrica de cuerpo sólido se había difundido ampliamente entre los músicos de jazz, rock y pop, pero era totalmente ajena al cine.

Todas estas novedades tímbricas, amén de llamar la atención del espectador de la época por lo inhabitual, ganan coherencia al equipararse a las renovaciones puramente cinematográficas del género: un sonido nuevo para una nueva forma de contar el Oeste. La implicación de Leone en la configuración de la banda sonora es ya un indicio de un modo integrador y global de pensar cine y música. Dada la cercanía en el tiempo entre las tres entregas de la trilogía (de 1964 a 1966), la evolución del tratamiento musical entre ellas es relativa y no se manifiesta en todos los sentidos. Es ilustrativo escuchar seguidas, por ejemplo, las piezas de créditos iniciales de las tres películas. La duración de las tres oscila entre tres minutos y dos minutos y cuarenta segundos. Las tres comparten rasgos estructurales y plantillas instrumentales similares: todas se componen de una suma reducida de motivos melódicos breves y superponibles sobre un ostinato rítmico de la caja, que remeda siempre el galope con la figura . . .5 . Las tres incorporan guitarra eléctrica, con un aumento progresivo en la ganancia (luego se verá en Hasta que llegó su hora), y las tres conceden importancia central al silbido y los coros sin palabras.

¿Hay diferencias? Por supuesto. Los ruidos extra-musicales de la primera desaparecen, mientras que sólo en la segunda nos es dado escuchar un arpa de boca, un instrumento también un tanto irreverente. En El bueno, el feo y el malo (II buono, il brutto, il cattivo), por otra parte, el rango tonal se amplia y la alternancia de motivos breves se vuelve más compleja y rápida, presentando una gran variación tímbrica. Es la banda sonora más corta y, sin embargo, la que más material musical contiene, además de mostrar mayor dominio compositivo; su complejidad, en definitiva, se acompasa necesariamente a la del filme. Por otra parte, nove- 
dades destacables como el uso del órgano remedando el BWV 565 de Bach en la iglesia de La muerte tenía un precio (Per pochi dollari in piu), son ensayadas una sola vez y dejadas de lado en el futuro.

Considerar estas particularidades como meras rupturas de la norma, o la ruptura de la norma como el móvil de las mismas, es tener en muy poco la labor del cineasta y el músico. Lo que sugieren estas primeras aproximaciones es lo que luego confirma un análisis más detenido, esto es, que los dos italianos optan por una elección libre y sin complejos de sus recursos estéticos, y que el hecho de que estos sean más o menos rompedores es indiferente. Retomamos así la idea de Adorno/Eisler sobre la circunscripción de cada música a los propósitos concretos de un film: Leone quería su propio western, y una música que le ayudara a configurarlo, sin preocuparse por la forma de conseguirlo

Ahora bien, aunque ya desde el primero hubieran logrado originalidad y acompasamiento de la música a los propósitos del film, ¿qué sucede con la otra condición general propuesta por los teóricos? ¿Se puede hablar de un "exceso de música" en la trilogía, de una producción sobrante cuya única función sea de acompañamiento, sin un aporte semántico destacable? La respuesta es positiva: las tres películas muestran una carga notable de música puramente incidental, "de relleno", y cabría plantearse si esto empobrece el resultado artístico de las mismas.

Podemos volver a la cita de James que encabeza el artículo para comprender mejor la factura de estos primeros westerns: todo su lenguaje, desde el guión hasta la fotografía o el omnipresente poncho de Clint Eastwod, permite lecturas diversas y muestra estándares altos de calidad, pero a la visión de Leone del género es inherente cierta espectacularidad, una vertiente del cine que es sólo forma y brillo, como ha sabido ver Thoret: "el gozo estético, el placer por la forma y la celebración de ese juguete rutilante que es el cine caracterizan sin lugar a dudas la obra de Sergio Leone" (2008:8). Pero precisamente a través de esta maniera "supo devolver al western una segunda vida y, al apropiarse de sus mitos y su retórica, asegurarle finalmente la supervivencia" (Íd). La verdad es que esto ya lo había hecho John Ford: no es tanto que el western necesitara a Leone como que Leone hizo bien al western, al que necesitaba. "El cine es el mito integrado en una fábula. No es la Industria del Sueño, es la fábrica de Mitos" (Leone, apud. Aguilar, 137). Bien entendido este objetivo, que Leone efectivamente lograría, viene de suyo que para forjar nuevos mitos el género necesitara de nuevas herramientas.

Por ello la trilogía será, en cierto modo, un campo de pruebas para muchas de esas técnicas. En Por un puñado de dólares, por ejemplo, comienza a ensayarse un uso tímido del leitmotiv, identificando la figura del Hombre sin Nombre (y sobre todo sus triunfos, como la resolución del duelo final) con el tema de los créditos iniciales; una asociación que nos permite, también, colegir que, si ésa es "la música del Oeste", la que identifica el marco narrativo y el modelo de mundo elegido para la ficción, el personaje de Eastwood es el oeste, un arquetipo que aglutina valores y características definidas por Leone. La identificación entre el héroe lacónico y la música de los títulos de crédito será un denominador común en las tres películas.

Leone dependerá, además, tanto de su amplia formación como de otras artes para urdir las redes referenciales de sus películas. Los ataúdes que Clint Eastwood contempla a su llegada a ese pueblo dominado por la muerte, por ejemplo, donde sólo tienen trabajo el enterrador y el campanero, son extremadamente parecidos a los que aparecen sujetos por las legiones de esqueletos en El triunfo de la muerte, de Brueghel el Viejo. A través 
de su bagaje artístico ${ }^{3}$ y su audaz lenguaje visual, Leone reformula los tópicos del género, como la muerte violenta, en cuyo tratamiento muestra respeto y un cuestionamiento moral implícito. Así construye un Oeste marcadamente ficcional pero dotado de complejos y veraces códigos morales: "Sergio Leone", ha sabido ver Thoret, "no es un cineasta del "o" (concepción clásica del mundo), sino del "y" (concepción moderna)" (54); la ambigüedad moral de personajes como el Hombre sin Nombre nombre es más veraz de lo que parece revelar su condición de "tipos", y alcanzará la plenitud en Hasta que llegó su hora (C'era una volta il West).

Esta complejidad moral se hace patente especialmente en el personaje del Indio en La muerte tenía un precio, una pieza que multiplica la complejidad narrativa de su antecesora y la de sus protagonistas, en una ficción oscura que Aguilar considera "de sesgo litúrgico y fatalista" (199). A nivel narrativo, el recurso novedoso en esta película es el flashback, imprescindible para dibujar con precisión al torturado personaje del Indio (Gian Maria Volonté), cuyo protagonismo en el film llega casi a eclipsar a Van Cleef e Eastwood, siendo él sólo antagonista de ambos. Otra prueba de este logrado retrato de Leone es lo difícil que resulta no percibir la conexión, y sobre todo en su dimensión musical, entre los personajes del Indio y el Noodles de Érase una vez en América. Además de que ambos cargan con el estigma de la violación, ambos son toxicómanos que recurren al opio (es de suponer que lo sea también lo que fuma el Indio) como medio de evasión, y el objeto de las ensoñaciones que les provoca a ambos es un pasado donde la imagen de la mujer deseada ocupa todos los espacios.

La diferencia principal es que el Indio aparece como un personaje mucho más torvo y toscamente dibujado. Sus ensoñaciones no se centran en una imagen ideal de la mujer deseada, sino en el momento mismo de la violación, quizá motivada por la previa pérdida de idealidad de la joven vista en la cama con otro. Noodles, por el contrario, echa el ancla de sus delirios en época más lejanas, en la adolescencia y las miradas a hurtadillas desde el baño, y su dibujo psicológico, rico y complejo; en realidad, más que un personaje de la película, Noodles es la película, como ocurría con el Hombre sin Nombre en la trilogía del dólar.

No obstante, de nuevo el enlace más relevante entre ambos personajes es que estos anclajes en el pasado están marcados por la música: en el caso del Indio, por la melodía entre tétrica e infantil del carillón, y en el de Noodles, por la canción que suena cuando Deborah ensaya y se desnuda para él: Amapola, para la que Morricone desarrolla diferentes arreglos a lo largo de la banda sonora. Ambas músicas se integran así en el tejido cronológico de los films, y, como el recuerdo para los dos drogadictos, sirven para el espectador de anclaje a los puntos temporales necesarios.

Pero si Amapola centra su función en esto, dejando la letra al margen de momento, el motivo del carillón del Indio amplía sus posibilidades significativas cuando éste lo instaura como una herramienta de muerte, que debe marcar el tiempo en la ejecución de su antiguo captor y en el último duelo, un duelo que por la distribución de los actantes y el espacio circular ya prefiguraba el de El bueno, el feo y el malo.

Además, es la raíz musical del que podríamos llamar "tema de la droga". Cuando en la aldea de Aguascalientes uno de los bandidos le pregunta acerca del significado del reloj, el Indio vuelve a recordar: junto con los agudos de los violines, el tema se compone de la me-

3 "Generalmente, parto de pintores a la hora de elaborar con Tonino la tónica visual de cada película. Para Érase una vez en América partimos de Norman Rockwell, Edward Hopper y Reginald March..." (Apud. Aguilar, 154). 
lodía del reloj invertida y atropellada, lo cual acentúa el carácter regresivo de la melodía. Se enuncia también con la guitarra, en un plano secundario, cuando el personaje de Van Cleef recuerda el episodio. A pesar de mediar sólo un año respecto a la primera entrega, Leone ha ensanchado ya el alcance referencial de su cine y su abanico de técnicas, pasando del universo más bien maniqueo del poblado azotado por la muerte de Por un puñado de dólares a un Oeste más real, menos "de cuento", y mucho más crudo para el espectador.

Y es que, desde Por un puñado de dólares a El bueno, el feo y el malo, hay un proceso de madurez intelectual del cine de Leone. Aunque domina el espectáculo, los espacios donde se ubican las acciones son cada vez más amplios y los temas más reales, de modo que en la tercera película el Sur de los Estados Unidos aparece como una realidad vívida y amplia, y más a medida que avanza la cinta. La guerra es probablemente el mecanismo que mejor articula esta entrada irrefrenable de la realidad en la ficción, como señala Thoret: tras la fuga del campamento sudista, Tuco y el Rubio recorren una ciudad en ruinas cuyo silencio se ve invadido progresivamente por el ruido de las bombas y los tiros: la violencia y su avance tienen aquí una dimensión sonora que define un acercamiento y un acecho desarrollado en el fuera de campo.

Para hacer justicia a la visión de Leone acerca de la guerra, no hay mejor ejemplo que "Historia de un soldado", canción que Morricone compuso logrando un sabor folk inconfundible; en una banda sonora saturada de sonidos agresivos, trompetas y guitarras, el romano elige una instrumentación cálida y amable con cuerdas, maderas (oboe y flauta) y arpa. La letra original de Tommie Connor enlaza con el logrado escenario final, el cementerio de Sad Hill (la traducción es mía): "contad todas las cruces y las lágrimas/las pérdidas y los recuerdos tristes [...]/¿Cómo acaba la historia, de quién es la gloria?/Preguntad, si osáis, a los camaradas que duermen allá fuera" ${ }^{4}$.

La canción, que sonará sin letra de nuevo hacia el final, cuando el Rubio comparte su cigarro con el soldado agonizante, se escucha por primera vez en el campamento nordista, mientras torturan a Tuco en la cabaña de Ojos de Ángel. Se produce así un efecto de doble contraste que acentúa tanto la violencia de la paliza como la tragedia de la guerra, desembocando luego en lo que llamamos efecto anempático, una experiencia "no de distanciamiento sino de emoción multiplicada, por el que la música, tras una escena particularmente dura (asesinato, tortura, violación, etc.) afirma su indiferencia, continuando su curso como si nada hubiera pasado" (Chion, 233). Este recurso será retomado en Érase una vez en América, tras la violación de Deborah, y sobre todo al final del film.

En esta primera etapa de su producción, Leone y Morricone sientan las bases de una poética propia, de un universo visual y auditivo que lleva su firma. El mayor impacto de la música, en estas películas, había sido en un primer momento la innovación tímbrica y la frescura y libertad de las estructuras musicales, pero a partir de la segunda entrega comienzan a verse en funcionamiento mecanismos más ambiciosos, algunos empleados con maestría, que anticipan lo que habría de venir en los próximos trabajos de los italianos.

4 La letra, reducida en la versión para cine, es la siguiente: "Bugles are calling from prairie to shore./Sign up and fall in and march off to war;/blue grass and cotton burnt and forgotten.../All hope seems gone so, soldier, march on to die./There in the distance a flag I can see,/scorched and in ribbons but whose can it be?/How ends the story, whose is the glory?/Ask if we dare our comrades out there who sleep".

Quaderns, 8 (2013), pp. 19-30 


\section{MÚSICA, TIEMPO: HASTA QUE LLEGÓ SU HORA Y ÉRASE UNA VEZ EN AMÉRICA}

Terminada la trilogía, Sergio Leone maduraba ya el proyecto de Érase una vez en América: rodar Hasta que llegó su hora fue la condición impuesta por la productora para poder dedicarse a ella con libertad. De modo que en 1968 Leone ya había leído The Hoods, libro en que se basa la película, y cuando se le ofreció dirigir la primera parte de El padrino (antes que a Coppola) la rechazó; tanto era su interés por contar su propia tragedia de gángsters americana. Pero si la tardía y forzada ¡Agáchate, maldito! (Giù la testa!) sí fue una incomodidad y un compromiso del que Aguilar no considera rescatable ni la música (Vid. pp. 221 y ss.), no ocurrió así con su último western, que sirvió como compendio y sublimación de las artes probadas en la trilogía anterior, y como coherente principio de una segunda trilogía, de la que el centro sería la formación y disolución de una idea casi soñada de América, aprehendida en la Roma de posguerra: "como otros directores europeos (pienso en Truffaut), yo he estado hipnotizado por la idea mítica de América. Una idea fuerte y ejemplarmente desilusionadora" (Leone, apud. Aguilar, 150).

El trabajo de Morricone para la cinta, por su parte, estuvo a la altura del proyecto; a juicio de Leone, fue la cima de la colaboración entre ambos:

La mejor banda sonora es Hasta que llegó su hora. Genial. Logró superarse a sí mismo. La combinación de humor y tragedia que consiguió conduce a una reconsideración de la música en el cine, y supone la distribución de las responsabilidades musicales más complejas que puede afrontar un gran compositor. Nunca en la historia del Western se había encontrado tal riqueza de temas y ritmos. En la película no existe ni una sola intervención musical que no encierre un sentido específico dentro de la historia (Apud. Aguilar, 148).

Tal vez la última frase resulte algo exagerada, pero la primera es indiscutiblemente cierta. De todos modos, la mayoría de los recursos empleados por Morricone en la película son desarrollos de los principios asentados en las anteriores; evidenciando, eso sí, una sabia moderación en su uso. "El socarrón y mediterráneo eclecticismo musical", en palabras de Aguilar, "deja paso a un personalísimo y realmente exquisito concepto del sinfonismo, que tanto parece desentrañar hasta la médula el significado de cada secuencia como dictar, incluso, el propio montaje" (61). En efecto y precisamente a partir de estas cintas, la música se convierte para Leone en una parte a priori, en parte del esqueleto del filme y no de sus pinceladas finales. Durante el rodaje de Érase una vez en América, De Niro y Woods estaban encantados de poder escuchar la música de la película mientras grababan sus escenas; es de suponer que así la música marcaría no ya sólo el ritmo narrativo y los cortes del montaje, sino que incluso modularía in situ las interpretaciones de los actores.

De vuelta al último western del director, Thoret lo quiso definir como una "apoteosis del estilo Leone", con un tratamiento temporal y fotográfico que para el crítico francés generan "la sensación de un mundo congelado y desierto, ya muerto en suma" (61); estos valores elegíacos son discutibles, pero es cierto que el film empieza a presentar una dimensión cronológica (y una extensión) más cercana a Érase una vez en América que a sus predecesoras. De todos modos, si no de réquiem, la obra sí tiene para Leone valor de compendio y cima de una época creativa: "Hasta que llegó su hora es un ballet de muertos, que tiene por material dramático todos los mitos tradicionales del Western: el vengador, el bandido romántico, la 
puta, el empresario pérfido, el criminal. A partir de estos cinco símbolos, se cuenta el nacimiento de una nación, determinado por la concepción japonesa del tiempo y la muerte" (Apud. Aguilar, 153).

El tiempo será, precisamente, la dimensión más importante en las dos últimas grandes obras de Leone y Morricone; después de todo, la música y el cine (que Deleuze llama "la imagen-tiempo") son las dos artes temporales por antonomasia: suceden, se desarrollan, y si no lo hacen, no son. Las similitudes en el tempo narrativo entre ambas cintas, por otra parte, derivan también del carácter "de cuento" de ambas. Si la costumbre española de inventar títulos grandilocuentes había estropeado el juego entre las entregas primera y segunda del dólar, este patético Hasta que llegó su hora tiene el valor de anunciar la importancia de la dimensión temporal en el film y parte del desenlace, pero elimina la cohesión naciente y las implicaciones ficcionales que habría tenido un apropiado Érase una vez en el oeste.

Uno de los recursos ensayados en las primeras películas, muy desarrollado en Hasta que llegó su hora, es el del leitmotiv: a Cheyenne se le identifica con un tema desenfadado y saltarín, que retoma el silbido y se acerca a la progresión de acordes del tema central; Bronson tiene su harmónica, y a Frank y sus matones les corresponde un motivo punzante de guitarra eléctrica. A Jill, por su parte, la asociamos con el mencionado tema central, enunciado ya en los créditos iniciales y reformulado en "Jill's América" (ver B.S.O.). Es notable como Morricone elige la trompa como voz cantante cuando el tema va más ligado a la ciudad soñada por McBain y la utopía americana, y una voz femenina cuando el centro de la acción es Jill (Claudia Cardinale) como ser humano.

No obstante, las grandes virtudes (dos) de la música es su imbricación en el universo referencial de la cinta, siempre centrada en el tema de Armónica. Hay una continua porosidad entra la dimensión musical, que el espectador normalmente percibiría como algo ajeno y que acompaña, y la dimensión narrativa de la acción: esta disolución de la frontera se debe a la convergencia de la música incidental y no incidental, una convergencia que comienza en el mismo principio de la cinta. El gañido de las maderas del molino y el silbido del tren son sonidos cercanos (incluso en su frecuencia y altura) al tenso motivo de la armónica, de modo que afianzan las raíces de lo musical en la acción real de la película: en un plano inconsciente de la percepción del espectador, el motivo de la armónica y todos sus desarrollos quedan directamente relacionados con la percepción de lo real-narrativo, y la sensación de inmersión en el filme es mucho más intensa.

Conviene recordar la secuencia nocturna en que Bronson acude a rondar la casa de los McBain. La mirada de Jill y la del espectador se unen, y en ese momento todo lo que tenemos para trabajar es la oscuridad del desierto, la brasa del cigarro flotando en ella, y el ostinato de la harmónica sonando: el nivel de abstracción que alcanza el cine en este momento es altísimo, y se prescinde totalmente del lenguaje hablado, y casi de la imagen. Los valores de despersonalización de Armónica, además, son un tema fértil, sobre todo si lo comparamos con el Hombre sin Nombre de la trilogía: ambos carecen de nombre conocido, van y vienen de forma errática; siempre llegan a los pueblos, siempre desde fuera. Ambos comparten la ausencia de ataduras con los vivos, y ambos se definen antes a través del tiempo que del espacio: son seres en continuo desplazamiento. "La gente como él", advierte Cheyenne a Jill refiriéndose a Armónica, "no es como los demás. La gente como él tiene algo que ver con la muerte". A falta de un nombre, los personajes encarnados por Eastwood y Bronson son la música que les acompaña en la pantalla. 
La otra labor impagable de la música en el film, y seguimos hablando sólo del motivo de la armónica, es similar a la del carillón del Indio en La muerte tenía un precio: enlaza, cada vez que suena, con el recuerdo oscuro que devora al personaje de Bronson. El acierto de Leone está, aquí, en reservar para el final la revelación exacta del anclaje, precipitando así la muerte del pasado y la del presente, y logrando lo más parecido a una catarsis que puede caber en un Western, un género que según él había inventado Homero.

La fragmentación de los motivos musicales permite la superposición de los tres motivos en la mezcla final, disparando la intensidad de la secuencia que enlaza las dos muertes que son motor y cierre del film: el gran número del "ballet de muerte" al que se había referido el director. La última muerte, la de Cheyenne, viene a retomar ese carácter elegíaco que señalaba Thoret, y acaba de decantar las simpatías del espectador: Cheyenne era un bandido entrañable, como lo era el Hombre sin Nombre de la trilogía del dólar: sujetos violentos y con poco respeto por la ley, pero con códigos morales definidos, amplia capacidad de sufrimiento y cierto sentido del humor. Una vez más, y sustentados por la sonoridad particular de los temas musicales que les acompañan, observamos que estos personajes son la quintaesencia y la concentración del Western de Leone.

Los valores de muerte del tema de la armónica lo vinculan estrechamente al tema de la flauta de pan en Érase una vez en América. En un documental de la BBC (Ennio Morricone, 1995), Morricone cuenta cómo ya había usado la flauta de pan con valores muy similares en Casualties of war, de De Palma, donde para él su timbre tenía "un fluir como de muerte, como de un pájaro cayendo a la tierra", en una escena en que los soldados asesinan a una muchacha vietnamita. En Érase una vez en América ocurre algo muy similar: aunque es un tema recurrente en la película, cuando se da con mayor intensidad es cuando Bugsy dispara sobre el niño, que cae sobre los adoquines a cámara lenta, sin otro sonido que el de la música ocupando todo el espacio auditivo. Por otra parte, uno de los muchachos de la banda lleva siempre en la boca, desde chico, una pequeña flauta de pan de metal, que recuerda a la armónica de Bronson y al carillón del Indio, donde a veces toca el mismo tema errático, que sólo significa para el espectador.

De hecho, la similitud de ambos motivos está en su misma forma musical, en su estructura rítmica esencial y sus intervalos: dos células que permiten desarrollo y fragmentación, y variación tonal amplia en el fondo armónico. Así, el motivo de la harmónica actúa a veces como base rítmica en ostinato, repitiéndose de forma cíclica (el asesinato de los McBain, la muerte de Frank), mientras que el motivo de la flauta, cuando se desarrolla en la banda sonora, es un bucle de sí mismo en brusco accelerando.

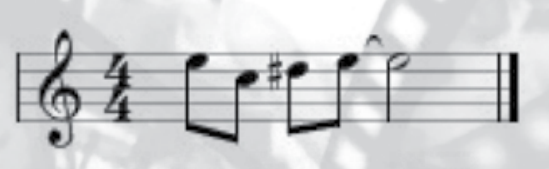

1. Hasta que llegó su hora

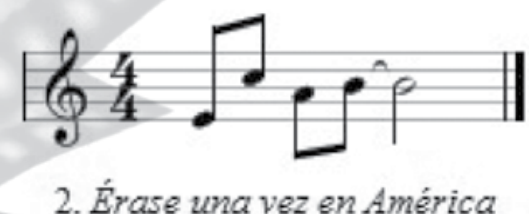

2. Érase una vez en América

La sencillez de ambos motivos, aquí presentados en su forma más esencial (el motivo 1, especialmente, sufre numerosas variaciones rítmicas en la película), tiene dos ventajas principales: la versatilidad de los mismos, como ya se ha dicho, y su fácil retención por parte del espectador. 
En el plano musical, Érase una vez en América destaca también por su uso prolijo y sabio del silencio. Según su cine se acerca más a la realidad, Leone va recortando cada vez más los fragmentos de música de mero acompañamiento. Así, aunque con la "Canción del soldado" superpuesta a la paliza en El bueno, el feo y el malo lograra un efecto notable, en estas últimas películas optará por la ausencia de música para acompañar las escenas más crudas. En Érase una vez en América la violencia sucede en silencio, vestida sólo con su propio sonido, con la excepción de la muerte del niño a manos de Bugsy. Así, la violación de Deborah gana en dureza y refuerza su carácter de desatino, al carecer de una música que la mediatice. En Hasta que llegó su hora, sin embargo, Leone msotraba todavía un gusto abierto por el espectáculo y las muertes más señaladas, las de los McBain, el empresario del tren, y Frank y Cheyenne al final, van todas acompañadas de música. La intensidad generada, junto con el papel de la armónica, que ya se ha comentado, justifican de sobra dichas músicas, pero es cierto que el silencio se convierte en recurso muy rentable en la dilatada Érase una vez en América.

Por otra parte, el uso de la canción vuelve a ser relevante para Leone en esta pieza. La elección del Yesterday de los Beatles en Érase una vez en América es significativo. El arreglo de la canción para la banda sonora es un tanto empalagoso o cursi, pero la letra de la canción, en su sencillez pop, contiene casi todas las claves del devenir del personaje de Noodles, su mapa sentimental y vital: "Yesterday love was such an easy game to play/now I need a place to hide away/Oh, I believe in yesterday"; y más adelante, "Suddenly, I'm not half the man I used to be...". Desde luego, el ayer en que el amor era un juego sencillo es la adolescencia, y el coqueteo con Deborah; el lugar donde esconderse, el fumadero de opio, y el medio hombre, Noodles a su regreso a 1968. El resto de la letra permite también identificaciones sugerentes, pero es demasiado larga para comentarla aquí.

Con Yesterday se abre el apartado de las referencias musicales externas del film. El Summertime de Gershwin y el Night and day de Cole Porter probablemente busquen sólo ambientar un mínimo la película, aumentar la impresión de época; también el St. James Infirmary blues, anónimo tradicional, que acompaña a modo de marcha fúnebre al ataúd-tarta la noche en que cae la Prohibición. Sin embargo, el uso de la obertura de La gazza ladra de Rossini en las escena del intercambio de bebés es característico del humor negro de Leone; el Amapola de Lacalle, ya mencionado, cumple también diversas funciones en el film, y la letra se puede tomar en consideración también, si se desea.

Sin embargo, si hay una incorporación clave a la banda sonora, es la de God bless America de Irving Berlin. Suena durante los créditos iniciales, muy de fondo y a través de una radio, pero es importante sobre todo en el cierre del film, cuando el viejo Noodles de 1968 ha salido de la mansión y contempla el presunto suicidio del "secretario Bailey": las luces rojas del camión de la basura, como dos ojos en la noche, se funden con las luces delanteras de una caravana de coches llenos de gente que festeja. Según los coches se acercan, va entrando en fade in la canción de Berlin, en una escena de una ironía y una intensidad extremas. Luego la canción y los coches se pierden de nuevo en la oscuridad, y con ellos las últimas hilachas del sueño de Noodles.

Así en Érase... se puede decir sin exagerar que no existe el triunfo: si Max ha llegado a la cima de lo que podía llegar, vive sus últimos días obsesionado por el suicidio, y su "sueño americano" acaba en un camión de basura. Noodles, al contrario, traza su trayectoria vital como una lenta autodestrucción que, al fin, lo mantiene vivo. Deborah, por su parte, parece 
haber pasado casi todo el film huyendo del mundo que encarna Noodles, para acabar hundida hasta el cuello en el mundo de Max.

Lo cierto es que Noodles y sus medias tintas se presentan en la película como el único modo posible de vivir, la única alternativa. Quedarse a la sombra y al margen del sueño, renunciar al sueño, es lo que lo ata a la vida. Las sesiones de opio son un modo de evasión que separa sueño y vida, según se va alejando de la idea de vida como camino hacia el sueño: Max y Deborah permanecen en la senda, y sobre todo Max es finalmente hecho trizas (literalmente) por el sueño mismo.

\section{CONCLUSIÓN: ARTISTAS Y ARTESANOS}

Todo lo que la trilogía del dólar tiene de identitario, profundo y espectacular, tiene que ver con la música. El universo estrechamente delimitado de la primera entrega, el oscuro personaje del Indio en la segunda, o la emoción desatada por la guerra en la tercera, la frescura y contundencia que es común a todas ellas, no se comprenden sin la labor conjunta de los dos romanos. En Hasta que llegó su hora, la música de Morricone derribaba las barreras entra ficción y espectador y alteraba los presupuestos de referencialidad de la música; un solo motivo de cuatro notas tensaba las cuerdas y tramoyas de todo el film. En Érase una vez en América, por su parte, la música se hundía en la materia temporal de la película y se entretejía en ella, la sostenía, la modulaba.

Si Tarkovski, con su preferencia por la música electrónica, y John Cage (reconocida influencia de Morricone), cada uno por su lado, abogan por una disolución de las fronteras entre ruido y música (lo podemos considerar todo dentro de la categoría de sonido), se admite con ello la necesidad de una ordenación del sonido, sea o no obedeciendo a las leyes de la armonía clásica o moderna. Si todo es sonido y el sonido del cine, como su imagen, y esto es necesario entenderlo, es organizado y limitado, como lo es nuestra percepción de los mismos, volveríamos en realidad al punto de partida, y resultaría hasta snob la condenación automática del uso total o parcial de la banda sonora tradicional y sus recursos.

En el fondo, como ya se ha dicho, el punto de partida de Morricone y Leone es éste, con o sin reflexión preceptiva previa: todo vale. Y regresamos al germen de la trilogía del dólar, al uso de ruidos reales mezclados con la partitura nueva de la guitarra eléctrica... y así hasta el prodigio musical y visual de Hasta que llegó su hora, pieza que nos pide que volvamos a enlazar con Tarkovski. Obviamente no hay una verdad válida, sencillamente el modo de ver el cine de Sergio Leone es otro muy diferente, en el que aunque se pretende que impere el significado y la justificación semántica de la imagen, hay también sitio para la belleza y la estética, para hacer una película más bella sin que sea "estrictamente necesario".

Y, no obstante, Hasta que llegó su hora y Érase una vez en América comulgan con el concepto de música de Tarkovski: "lo que quiero destacar es la indeterminación. El tono sonoro debe mantenerse en una indecisión, cuando lo que se oye puede ser música o una voz o sólo viento" (189). Una música que brote del film debe hacerlo con naturalidad, proceder del film e integrarse plenamente en su tejido, no ser una capa posterior (o anterior). Deleuze piensa que entre música e imagen hay una correlación, "pero no se trata de una correspondencia externa -ni tampoco interna- que nos reduciría a una imitación"; por el contrario, "todos los elementos sonoros, incluida la música, incluido el silencio, forman un continuo como pertenencia a la imagen visual [...]. Con el sonido, la palabra y la música, el circuito de la imagen- 
movimiento conquista otra figura, otras dimensiones o componentes; mantiene sin embargo la comunicación de la imagen y de un todo cada vez más rico" (318).

Nos preguntábamos al inicio si se había logrado, en la obra de Leone y Morricone, esa comunión privilegiada de música e imagen, y si la misma trascendía, en su hechura y efectos, lo meramente mecánico y artesanal, para devenir en "algo más". La respuesta es que, tras la fachada brillante y efectiva del cine de Leone, tras la sencillez cantable de las melodías de Leone, se percibe una profundidad semántica y una solidez compositiva que trascienden toda voluntad comercial.

\section{BIBLIOGRAFÍA}

ADORNO, Theodor W. y Eisler, Hans (1981), El cine y la música, Madrid, Fundamentos.

AGUILAR, Carlos (1990), Sergio Leone, Madrid, Cátedra.

CAGE, John (2007), Silencio, Madrid, Árdora.

CHION, Michel (1997), La música en el cine, Barcelona, Paidós.

DELEUZE, Gilles (1996), La imagen-tiempo, Barcelona, Paidós.

NIETO, José (2003), Música para la imagen. La influencia secreta. Madrid, S.G.A.E/lberautor.

RADIGALES, Jaume (2008), La música en el cine, Barcelona, UOC.

TARKOVSKI, Andrei (2005), Esculpir en el tiempo, Madrid, Rialp.

THORET, Jean-Baptiste (2008), Sergio Leone, Madrid, El País/Cahiers du Cinema. 